This manuscript is a preprint and has been submitted for publication. Subsequent versions may have slightly different content. The DOI of the peer reviewed publication will be provided if accepted. Please contact the authors if you have any questions or comments on this manuscript. 


\section{Plastic plants: Water hyacinths as driver of plastic transport in 2 tropical rivers}

\section{Authors}

Louise Schreyers ${ }^{1 *}$, Tim van Emmerik ${ }^{1}$, Thanh Luan Nguyen², Evelien Castrop ${ }^{1}$, Ngoc-Anh Phung ${ }^{3}$, Thuy-Chung Kieu-Le ${ }^{3,4}$, Emilie Strady ${ }^{5}$, Lauren Biermann ${ }^{6}$, Martine van der Ploeg ${ }^{1}$

${ }^{1}$ Hydrology and Quantitative Water Management Group, Wageningen University, Wageningen, The Netherlands

2École Polytechnique de Montréal, Montréal, Canada

${ }^{3} \mathrm{Ho}$ Chi Minh City University of Technology (HCMUT), Ho Chi Minh City, Vietnam

${ }^{4}$ Vietnam National University Ho Chi Minh City, Ho Chi Minh City, Vietnam

${ }^{5}$ Aix-Marseille University, Mediterranean Institute of Oceanography (MIO), Marseille, Université de Toulon, CNRS/IRD, France

6Plymouth Marine Laboratory, Prospect Place, Plymouth, UK

${ }^{*}$ Corresponding author. E-mail: louise.schreyers@wur.nl

\section{Abstract}

Recent studies suggest that water hyacinths play an important role in the transport of macroplastics in freshwater ecosystems. Forming large patches of several meters at the water surface, water hyacinths tend to entrain and aggregate large amounts of floating debris, including plastic items. Research on this topic is still novel and few studies have quantified the role of the water hyacinths in plastic transport. In this study, we present the findings of a six-week monitoring

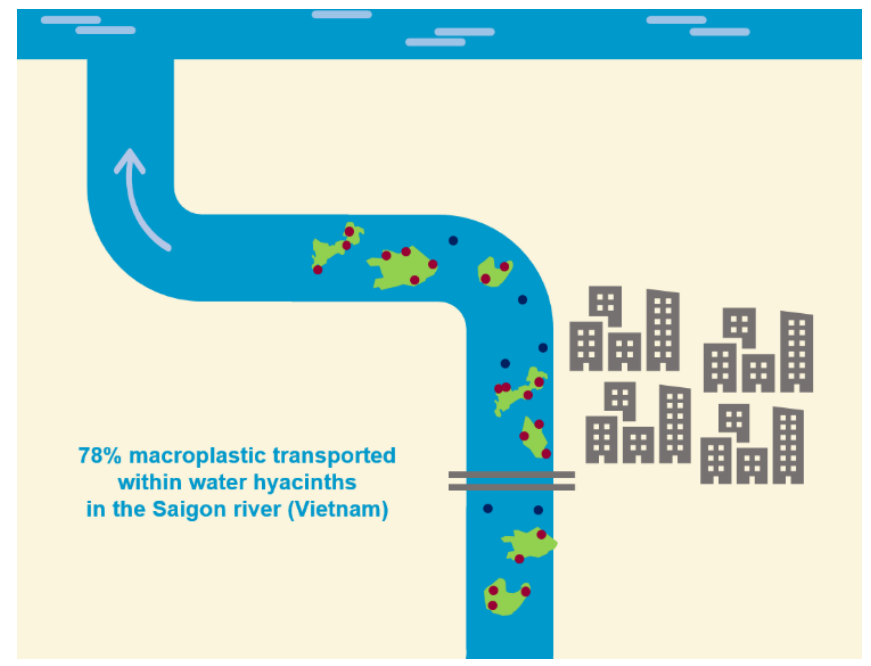
campaign, combining the use of visual observations and aerial surveys in the Saigon river, Vietnam. For the first time, we provide observational evidence that the majority of plastic is transported downstream by water hyacinths. Over the study period, these fast-growing and free-floating water plants transported $78 \%$ of the macroplastics observed. Additionally, we present insights on the spatial distribution of plastic and hyacinths across the river width, and the different characteristics of entrapped items compared with free-floating ones. With this study, we demonstrate the role of water hyacinths as a river plastic aggregator, which is crucial for improving the understanding of plastic transport, and optimizing future monitoring and collection strategies.

Keywords: macroplastic; microplastic; riverine pollution; aquatic vegetation; observations; field data 


\section{Introduction}

Rapid growth in plastic production and consumption has made plastic pollution an ubiquitous issue across the globe. Plastics can directly harm aquatic and terrestrial species, and cause serious economic damage ${ }^{1}$. Alarmingly, studies predict major increases in plastic emissions due to low recycling rates, global increases in plastic consumption, and difficulties in large scale plastic reduction efforts ${ }^{2,3}$. Plastic pollution monitoring efforts are being conducted at various scales, but these initiatives focus mostly on marine and coastal areas, rather than riverine ecosystems ${ }^{4}$. Despite rivers assumed to account for the majority of the plastic emitted into oceans ${ }^{5}$, many aspects on plastic transport and fates in river systems remain unknown. Yet, quantifying riverine plastic loads is essential for assessing the efficiency of plastic reduction measures such as reduction of plastic consumption and improving of waste disposal.

Understanding of the role of various factors in plastic transport variability in rivers is expanding, and studies are exploring different drivers for different sizes of plastic debris. It is often assumed that hydrometeorological variables are important drivers of plastic flux ${ }^{1}$. River discharge was related plastic transport in the Seine, France ${ }^{6}$ and changes in dry/wet seasons correspond to significant plastic debris fluctuations in the Wonorejo river, Indonesia ${ }^{7}$. In the UK, flood events were found to be responsible for microplastic export ${ }^{8}$. Other drivers, such as sediment loads have also been recently examined in Australia $^{9}$, China ${ }^{10}$ and Amazonian rivers ${ }^{11}$ in relation to microplastic transport. Mangrove forests and coastal vegetation habitats can also be an important sink of plastic debris ${ }^{12-14}$. In the Saigon river, Vietnam, macroplastic transport was correlated to the abundance of organic debris (mainly floating water hyacinths), rather than hydrological variables ${ }^{15}$. Both the abundance of plastic and water hyacinths were found to vary with an order of magnitude, suggesting hyacinths have a substantial influence on plastic transport. For better understanding of plastic transport dynamics in the (sub)tropics, exploring the role of water hyacinths is thus crucial.

Water hyacinth (Eichhornia crassipes) is a macrophyte species native from the Amazon, which has spread to most freshwater ecosystems in the tropics and subtropics ${ }^{16}$. Water hyacinths are aquatic weeds that tend to aggregate and form large patches floating at the water surface. They are considered one of the most invasive vegetation species in the world, and have already spread to 15 Asian and 36 African countries ${ }^{17,18}$. More recently, these floating water plants have been observed in North America and Southern Europe ${ }^{17,19}$. Despite water hyacinths being considered a nuisance, their absorbent capacities offer an opportunity to use them as ecological indicators, and their role in the absorption of pollutants such as heavy metals has been well ascertained ${ }^{20}$. Our interest in hyacinths in relation to plastic pollution is three-fold. Firstly, we hypothesize that hyacinths substantially influence spatiotemporal variation in riverine plastic transport. Understanding this relationship is key for improved plastic transport quantification. Secondly, the detectability of large floating vegetation aggregations from satellite ${ }^{16,21,22}$ is an opportunity to use hyacinth patches as a proxy for plastic pollution. This could be an important step in scaling-up plastic monitoring efforts. Lastly, if the role of hyacinths in aggregating plastic is ascertained, clean-up efforts could utilize the plant as a means for efficient plastic co-removal in inland waters. In this paper, we provide a first assessment of the role of water hyacinths in riverine macroplastic transport. We present findings of a six-week measurement campaign that combined visual 
observations and aerial surveys. We monitored the contribution of plastic entangled in hyacinths relative to the total plastic transport, the accumulation of plastics in hyacinths, and composition of plastics within and outside hyacinths. With this paper we aim to: (1) demonstrate the substantial role of water hyacinths in plastic transport, and (2) provide insights on the characteristics (polymer composition and size distribution) of plastics that are transported by hyacinths.

\section{Materials and methods}

We focused on the Saigon river, considered the $5^{\text {th }}$ most plastic polluted watershed in Vietnam ${ }^{23}$. The Saigon river is part of the Saigon-Dong Nai river system that traverses Ho Chi Minh City (HCMC). The Saigon river is controlled upstream by a reservoir and is subjected to diurnal asymmetric tides. Its net annual water discharge was estimated of $50 \mathrm{~m} 3 \mathrm{~s}-1$, fluctuated monthly from 4 to $222 \mathrm{~m} 3 \mathrm{~s}-124$. Plastic pollution in the Saigon river has already been monitored by several studies, thus enabling investigation of transport dynamics ${ }^{15,25}$.

We used two complementary measurement methods to quantify both the role of water hyacinths in plastic accumulation and in transport (table 1). Visual observations enabled to estimate macroplastic transport flux at the water surface for 15 days. Aerial surveys, on the other hand, allowed finer characterization on the plastic entangled in water hyacinths, such as spatial distribution along the river width, polymer composition, item size and plastic density within vegetation patches. Visual counting could be used for item polymer categorization, but becomes challenging in a context of high plastic flux ${ }^{25}$. The aerial survey uses photos and does not allow to calculate flux ${ }^{26}$.

The visual measurement campaign took place between the 27 April to the 8 June 2020. The plastic items counting protocol was adapted from the methodology developed by van Emmerik et al. ${ }^{25}$. The counting was done from the Thu Thiem bridge in HCMC $\left(10^{\circ} 47^{\prime} 08.3^{\prime \prime} \mathrm{N}, 106^{\circ} 43^{\prime} 06.2^{\prime \prime} \mathrm{E}\right)$, see fig. 1 . The aerial measurements were taken on the 23 May 2020 only. A total of ten UAV flights were conducted on that day, with the four initial flights $100 \mathrm{~m}$ downstream the bridge, and the six subsequent surveys $80 \mathrm{~m}$ upstream. The aerial survey method that we present is similar to the method tested by Geraeds et al. ${ }^{27}$, with the alteration of splitting the cross-sectional flights to two locations, due to tidal influences.

Table 1. Overview of methods used to characterize macroplastic transport and storage in water hyacinths for the Saigon river

\begin{tabular}{|l|l|l|l|l|}
\hline Method & $\begin{array}{l}\text { Temporal } \\
\text { coverage }\end{array}$ & $\begin{array}{l}\text { Spatial extent per } \\
\text { survey }\end{array}$ & $\begin{array}{l}\text { Processing / } \\
\text { data analysis }\end{array}$ & Derived metrics \\
\hline Visual observation & $\begin{array}{l}15 \text { observations } \\
\text { of } 1 \text { day over a } \\
\text { 6-week period }\end{array}$ & $\begin{array}{l}45 \mathrm{~m} \text { among } 340 \mathrm{~m} \text { of } \\
\text { river width }\end{array}$ & $\begin{array}{l}\text { Extrapolation of } \\
\text { values for whole } \\
\text { river width }\end{array}$ & $\begin{array}{l}\text { \# items / min (entangled and free- } \\
\text { floating) }\end{array}$ \\
\hline Aerial survey & 1 day - 23 May & $\begin{array}{l}335 \mathrm{~m} \text { at two nearby } \\
\text { river segments (out of } \\
340 \mathrm{~m} \text { of river width) }\end{array}$ & $\begin{array}{l}\text { Manual labelling } \\
\text { and color filtering }\end{array}$ & $\begin{array}{l}\text { \# items in and out water hyacinths, } \\
\text { items size, polymer composition, } \\
\text { distribution along river width, } \\
\text { vegetation area, \# items } / \mathrm{m} 2\end{array}$ \\
\hline
\end{tabular}



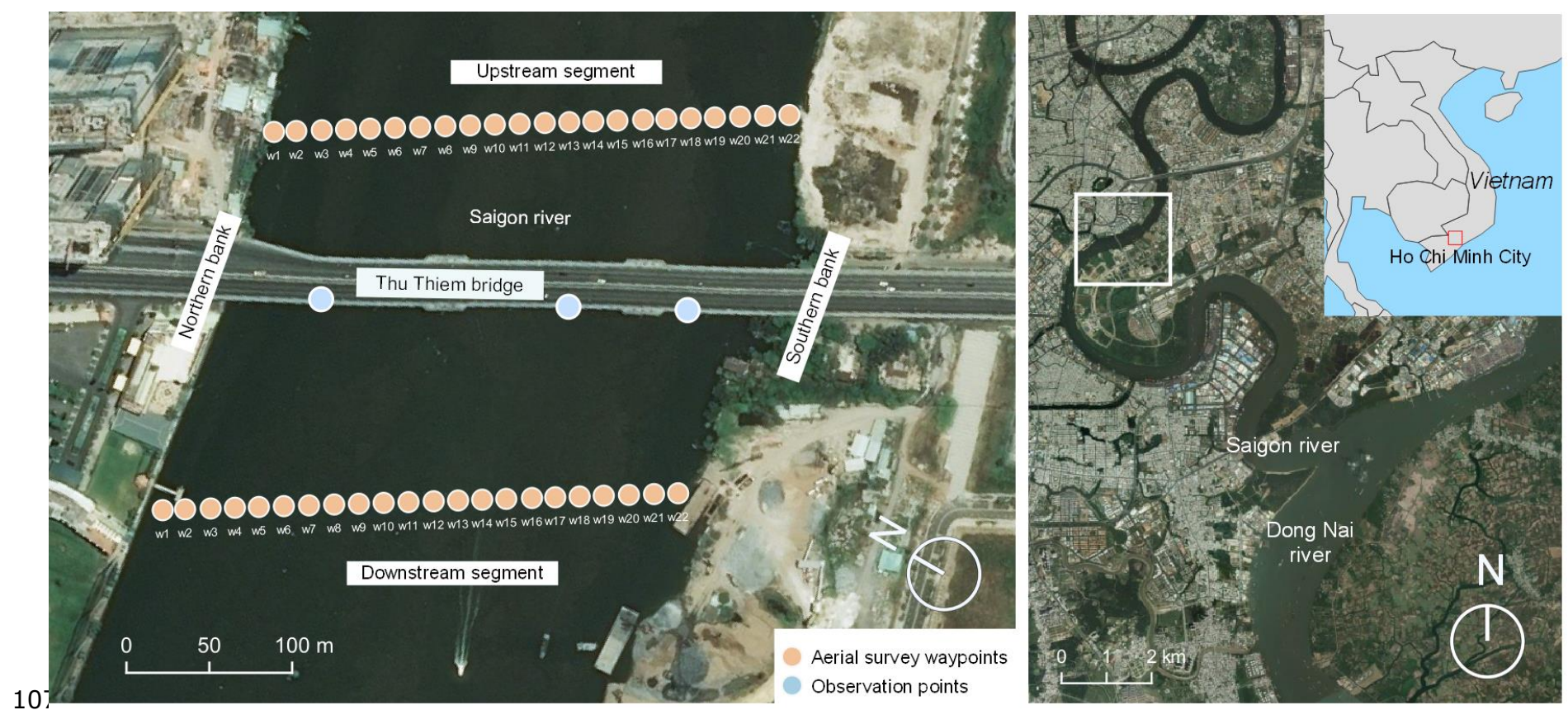

108 Figure 1. Localization of visual observation points and 22 aerial survey waypoints. Source: Bing 109 imagery.

\section{Visual counting for Temporal Plastic Flux}

111 The visual counting method was adapted from van Emmerik et al. ${ }^{25,28}$. It is a well-established and simple

112 observation procedure, easily replicable at various locations.

113 The visual observations were conducted from three different locations along the Thu Thiem bridge over 114 a period of 6 weeks. It is estimated that at each location, the surveyor was able to detect all floating 115 plastic items along a $15 \mathrm{~m}$ width section. Overall, $13 \%$ ( $45 \mathrm{~m}$ out of $340 \mathrm{~m}$ ) of the river cross-section 116 was covered by the visual counting. The bridge is approximately $14 \mathrm{~m}$ above the water level and the 117 counting was done facing downstream. During a time frame of two minutes and at one bridge location, 118 the surveyor counted all plastic items within vegetation patches (entangled). This observation sequence was followed by another 2-minute time frame to count plastic debris located outside (free-floating) of water hyacinths. If the nature of the debris was uncertain, it was not counted as a plastic item. After the visual counting at one observation point, the surveyor proceeded to the next one. For each measurement day, several profile of the bridge were done. Subsequent data analysis included extrapolation of plastic flux for the whole river width and scaling to obtain hourly values (text S1).

\section{UAV survey}

A DJI Phantom 4 Pro UAV (DJI, Shenzhen, China; http://www.dji.com) was used to acquire aerial imagery upstream and downstream of the Thu Thiem bridge on 23 May 2020. A total of 3,936 images were taken at 22 waypoints across the river width. Blurry images were discarded $(n=261)$ and ultimately, only images with visible plastic items were retained for analysis $(n=128)$. The low number of images analyzed is due to the removal of overlapping images at the same waypoint. When images taken at a waypoint showed differences in the number of plastic items, they were both analyzed, making sure that items present on both images were not counted double. 
The selected images were manually labelled with the open source Visual Geometry Group Image Annotator (VIA) tool ${ }^{29}$. Two categories of plastic were distinguished: "free-floating" items - plastic debris flowing freely at the river surface - and "entangled" items - plastic waste trapped within hyacinth. Rectangular polygons were drawn around each identified plastic item for size and area estimates (fig. S1). Information on the polymer composition was also filled in during the manual labelling. Seven polymer types were distinguished, following the categorization used in van Emmerik, Strady, et al. ${ }^{15}$ : (1) E-PS (expanded polystyrene), (2) PO hard (hard polyolefins), (3) PO soft (soft polyolefins), (4) PS (polystyrene), (5) PET (polyethylene terephthalate), (6) Multilayer plastics, and (7) Rest plastics. The items were categorized based on color, shape and other visual properties such as transparency. When the polymer composition of the item was uncertain, it was categorized as part of the category 'Rest'.

To estimate the aquatic vegetation coverage area, color filtering was performed using the Open CV library in Python over a selection of images $(n=75)$ (text S3, fig. S2). Ultimately, the ground sampling distance was determined, based on the flying elevation, the image width in pixels, sensor width and focal length of the camera (text S3). This allowed us to estimate both vegetation and plastic item areas.

\section{Results and discussion}

\section{Temporal variability in plastic items transport}

A

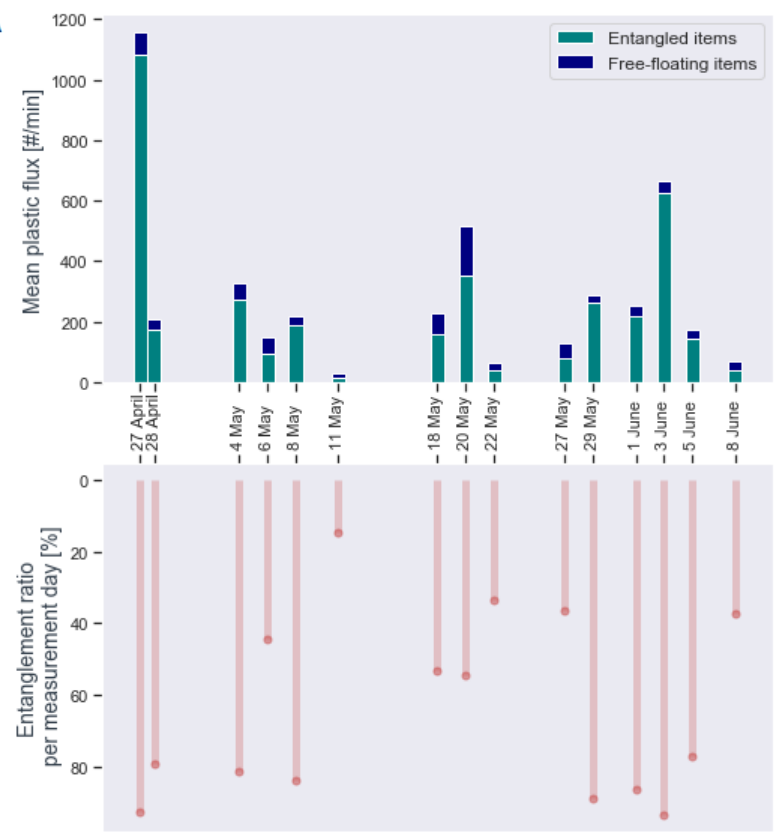

B

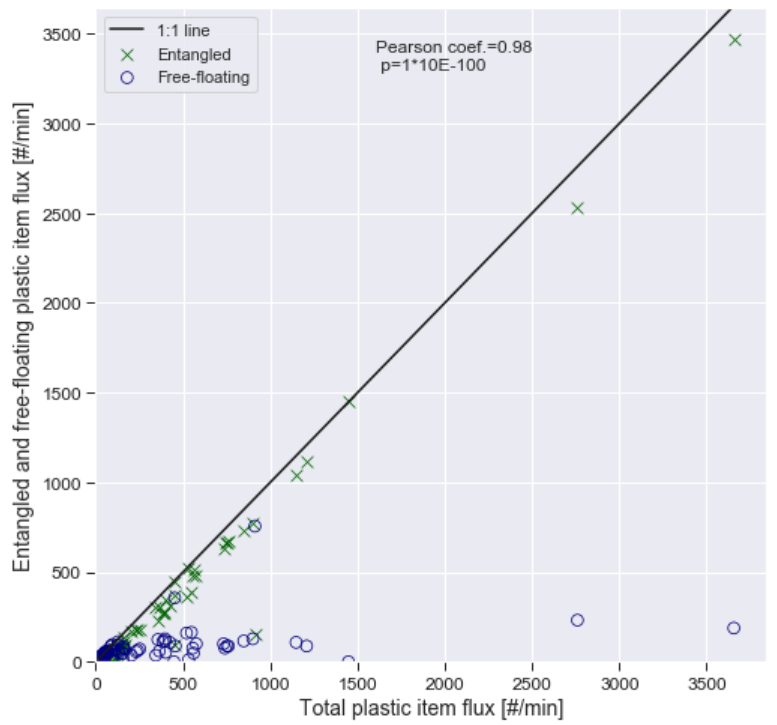

Figure 2. A. Mean plastic flux and entanglement ratios per measurement day as measured from visual observations. B. Entangled and free-floating plastic flux in relation to total plastic flux. Each data point represents one visual counting observation.

Estimated mean plastic flows show large temporal variability during the visual counting period. Mean daily plastic flux calculated from visual observations varied between 15 to 1,080 items/minute (fig.2A), with the lowest mean plastic flux on 11 May and peak mean plastic flux on 27 April. No steady and 
consistent temporal trend is noticeable over the 6-week period: days with low plastic flux can be followed by increases in plastic flux and then register a significant drop at the next measurement day.

The entrapped fraction of transported macroplastic varies greatly, from $15 \%$ to $93 \%$ depending on the measurement day (fig.2A), with days registering low ratios broadly corresponding to low plastic daily flux (6 May, 11 May, 22 May, 27 May, 8 June). In addition, we found that plastic transported by hyacinths shows a variability in mean flux of three orders of magnitude (2-1,002 items $/ \mathrm{min})$. This is considerably higher than the variability in free-floating flux, of one order of magnitude (12-160 items $/ \mathrm{min})$. These results suggest that the transport of plastic entrapped in hyacinths has a major influence on the total plastic transported along the river.

During the 6-week period of visual counting, water hyacinths transported an average of $78 \%$ of the observed plastic items. The mean plastic flux over the study period was estimated at $170 \mathrm{items} / \mathrm{min}$ for entangled items and 48 items/min for free-floating debris. Total mean plastic flux was thus approximately of 218 items $/ \mathrm{min}$.

We found a highly positive correlation between entangled plastics and total plastic items (fig. 2B), the latter being likely mainly driven by the amount of hyacinths flowing. Data on the transport of free-floating items, on the other hand, show a lower positive correlation $(r=0.48, p<0.01)$ with total plastic flux. These results suggest that total plastic transport in the Saigon River flanking Ho Chi Minh City is mainly driven by plastics accumulated in hyacinths.

For the month of May specifically, we estimate a total plastic flux of 162 items $/ \mathrm{min}$. Interestingly, this estimation is close to the mean flux values (117-133 items/min) found by van Emmerik, Strady, et al. ${ }^{15}$ for May 2018 at the same location. The slightly higher flux that we measured in 2020 might be attributable to variability in environmental drivers (for example, rainfall for water flow, temperature for hyacinth growth), increases in plastic consumption, mismanagement and leakage between observed years, and to the lower number of observation points along the bridge for the visual counting in 2020 . Higher transport flux at the location of the observation points compared to the rest of the river might have induced an overestimation of plastic flux along the river width. We recommend to proceed to visual counting at more locations in the future, for improved accuracy in the plastic transport estimates.

\section{Spatial distribution of plastic debris and water hyacinths}

The spatial distribution of plastic debris and vegetation captured by the UAV survey on 23 May shows large heterogeneity in hyacinth and plastic concentrations along the river width, with clear accumulation zones. For aerial surveys done downstream of the bridge, debris and vegetation patches accumulated in largest amounts close to the northern river bank at waypoint 1 . Approximately $57 \%$ of detected hyacinth patches, $40 \%$ of plastic items entangled in hyacinth, and $33 \%$ free-floating items were observed along the first $35 \mathrm{~m}$ from the northern river bank (fig.3A). Vegetation and plastic concentration zones were also observable at $80 \mathrm{~m}$ (waypoint 6) from the north river bank, and waypoint 16 at $230 \mathrm{~m}$ (closer to the southern river bank). For the section upstream of the bridge, concentration near the northern river bank is even higher (fig.3A). Most plastic items accumulated in the first $35 \mathrm{~m}$ from the north river bank ( $87 \%$ for entangled items and $74 \%$ for free-floating ones), with just a few items counted at waypoint 16 
covering 230-275 m. The hyacinths were all concentrated at the northern bank for the upstream surveys.

194 This can be explained by the higher number of plastic items detected over the $7^{\text {th }}$ flight $(n=193)$

195 compared to the average number of detected items for all other flights $(n=40)$.

196 Overall, it remains unclear if the observed distribution pattern is the result of the absence of hyacinths

197 in the mid-channel sections (given that this section of the river is heavily navigated) or if northern

198 sections are natural accumulation zones due to the combined influence of flow velocity, wind speed,

199 river shape and the presence of hyacinths. Understanding what determines the spatial distribution of

200 the water hyacinths could provide new insights on macroplastic accumulation zones and thus inform

201 plastic removal measures. 
A

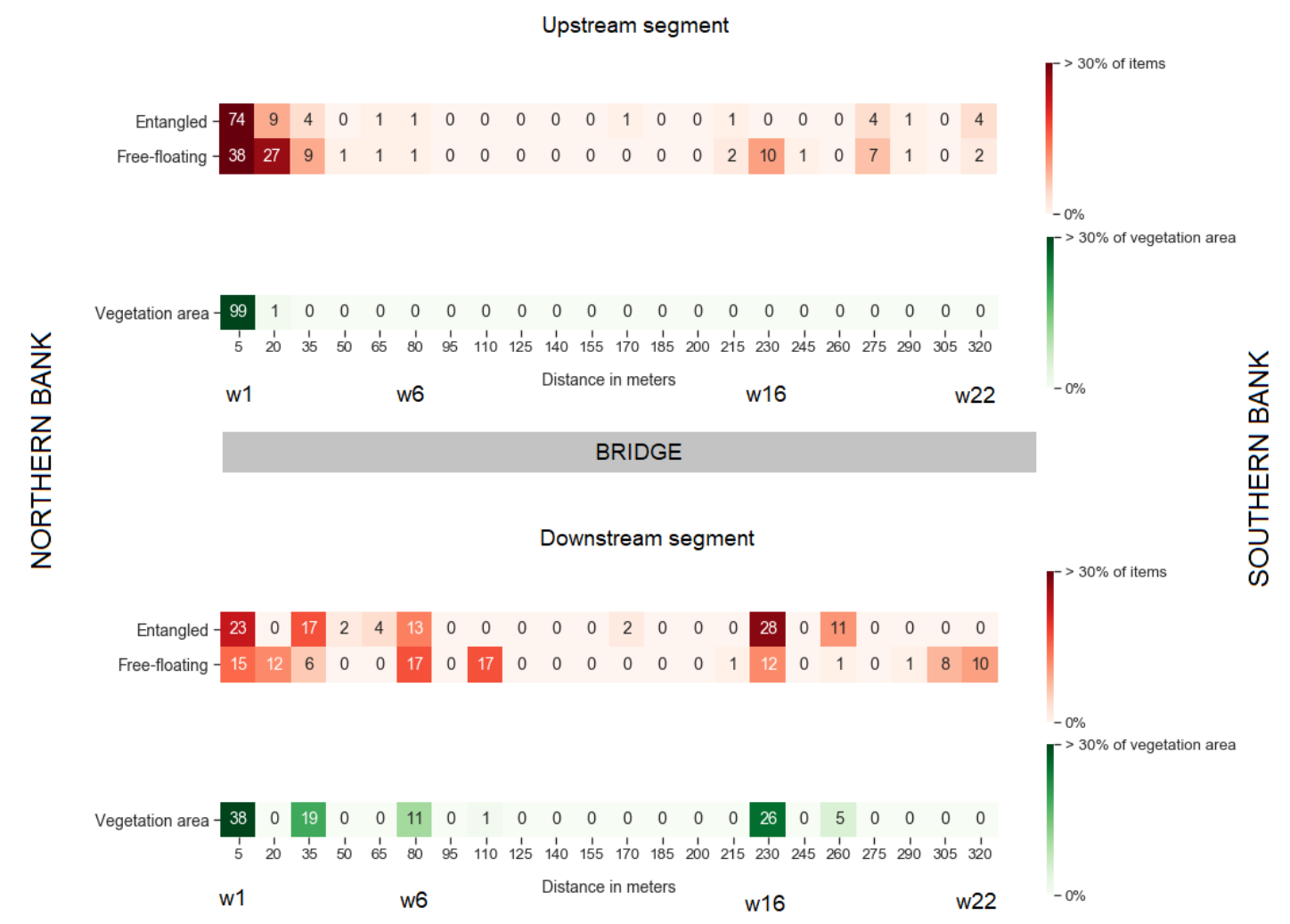

B
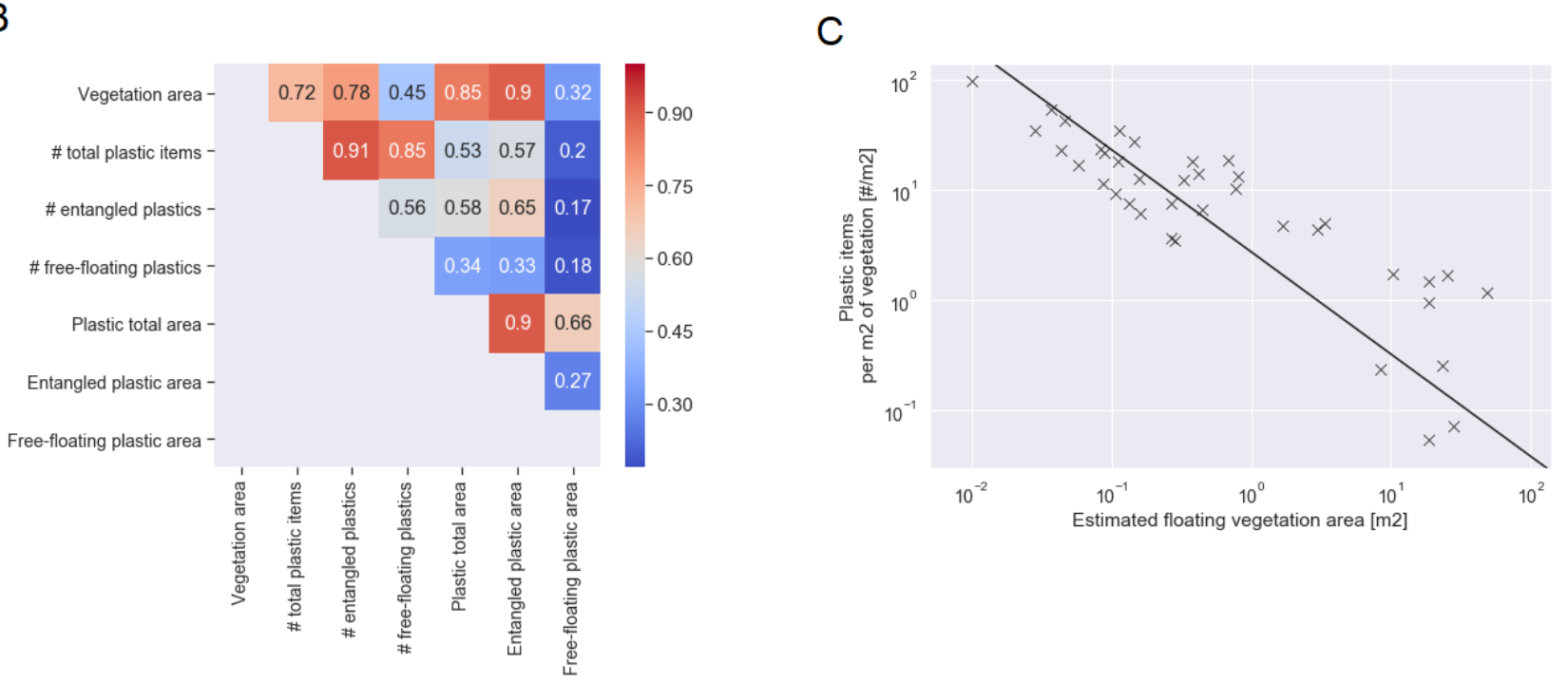

204 Figure 3. (A) Distribution of vegetation and macroplastics along the river width [\%] upstream and downstream the bridge. (B) Correlation matrix of measured metrics. Red shows highest correlation scores between variables, while blue shows lower scores. All p-values are $<0.01$ so all correlation scores show significant relationships between variables. (C) Plastic accumulation within hyacinth patches: number of plastic items per $\mathrm{m}^{2}$ of vegetation in relation to the estimated vegetation area in $\mathrm{m}^{2}$.

For the entire river width, the aerial survey found that $39 \%(n=313)$ of plastic were accumulated in hyacinth on the $23^{\text {rd }}$ of May. Considering only items of a size $>2.5 \mathrm{~cm}$, the entrapment rate rose to $44 \%$. 
Note that this 'snapshot' entanglement ratio cannot be compared directly with the ratio of entangled plastic flux measured over 6 weeks. Nonetheless, the UAV results on spatial distribution are consistent with the visual counting results on transport temporal variability: lower total transport flux on 22 and 27 May plus higher free-floating plastic transport compared with hyacinth-entangled flux.

Overall, the data (fig.3B) show that the spatial macroplastic distribution is strongly correlated with the hyacinth presence ( $r=0.72$ for the total plastic count and $r=0.85$ for plastic area) as well as with entrapped plastics ( $r=0.78$ for items count and $r=0.9$ for area). Furthermore, the area of entangled items is correlated to the size of the hyacinth patch $(r=0.90)$.

The accumulation of plastic in vegetation patches varies considerably, from 0 to 98 items per $\mathrm{m}^{2}$ (fig. $3 C$ ). On average, the accumulation density is 7 items per $\mathrm{m}^{2}$ of vegetation. Interestingly, the data show that largest vegetation patches have lowest plastic accumulation densities. Visual examination of the aerial imagery showed that plastic litter is mostly entrapped at the edges of the patches, with a sparser presence of items in the central area. This could indicate that free-floating items interact with the edges of the vegetation patches during their transport.

\section{Polymer composition and size distribution}

The plastic debris we detected in UAV imagery consisted mainly of E-PS (38\%), in similar proportions compared to previous studies conducted in the Saigon river ${ }^{15}$. The predominance of E-PS is the result of both the extensive use of single-use food containers in Vietnam ${ }^{30}$ as well as the high buoyancy and floatability of this low-density polymer type. E-PS made up for $32 \%$ of free-floating items and almost $49 \%$ of entangled items (fig.4A). Its low density might explain how and why it becomes entrained in hyacinth patches. Hyacinth appears to entangle PET items at higher rates compared with the proportion observed in open water, possibly because the items we observed in the UAV imagery were of a larger size $(>10 \mathrm{~cm})$. Overall, PET were the least abundant $(2 \%)$ polymer category, a likely effect of re-use or recycling mechanisms targeting this category of plastic debris. The share of items classified as 'Rest' is higher $(30 \%)$ within the hyacinth patches than outside $(21 \%)$. Poor identification of entangled plastic materials were likely caused by the partial coverage of plastic debris by leaves and roots. PS, PO soft and Multilayer items were more frequently observed as free-floating debris (respectively, 16, 16 and 6\%) than entangled (3, 8 and 1\%), indicating that bags and foil items are not easily entrained/ entangled. This may be due to the fact that PO soft items were predominantly below $1 \mathrm{~cm}$ in size, suggesting a higher level of fragmentation (fig 4B). Only PO hard particles were found in similar proportions in both entangled and free-floating items (respectively 8 and $9 \%$ ). This is a considerably lower estimate than found in previous studies, where PO hard accounted for approximately $20 \%$ of detected items ${ }^{15}$. Possible explanations for this could be observer bias from the manual labelling, or a relative scarcity of PO hard items during the measurement day (23 May). Given that plastic composition is subject to temporal variability ${ }^{15}$, higher temporal coverage and frequency on the polymer composition of entangled plastic items is needed to inform plastic reduction strategies. 

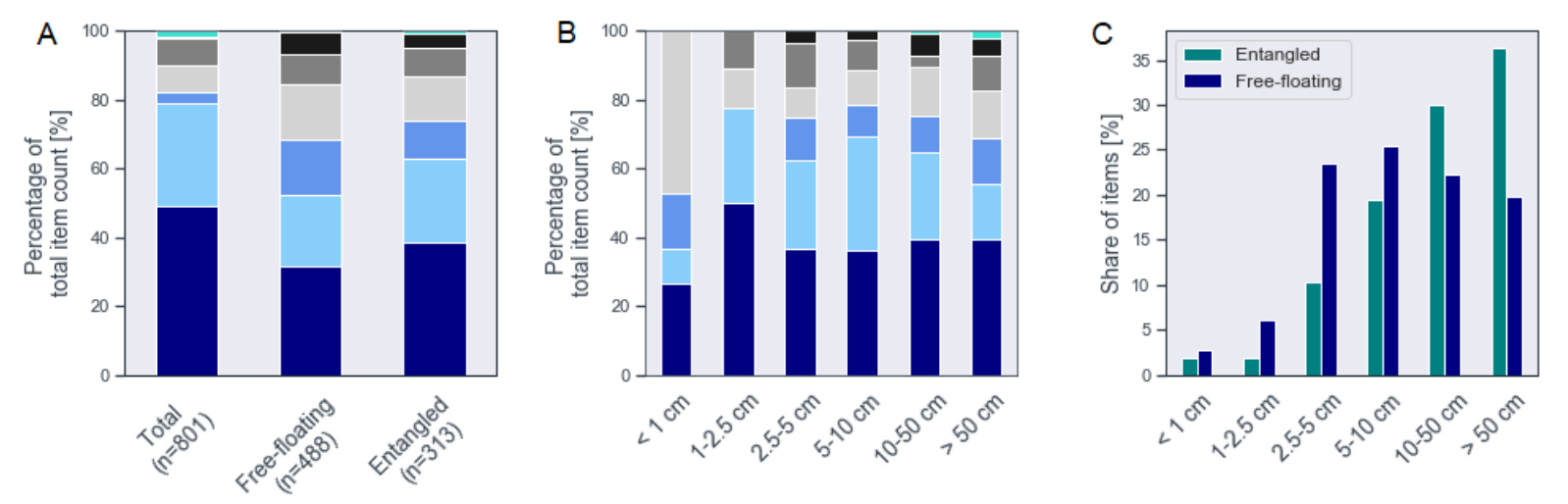

Figure 4. Polymer composition of plastic items (A), in relation to size categories (B) and overall size distribution $(C)$.

Overall, the hyacinths entrapped larger particles than otherwise observed in open-water (fig.4C). Around two-third of plastic debris within vegetation patches exceeded $10 \mathrm{~cm}$ in size, whereas two-third of freefloating debris were smaller than $10 \mathrm{~cm}$. There are two possible explanations for this. The first assumes that the plastic items have been flowing freely for some distance. During their transportation, the large items get trapped in the vegetation patches, due to contact and interference. On the contrary, the small debris items appear to be more mobile on the water surface, and perhaps more influenced by flow. The second explanation considers that most of the plastic litter is leaked into the river system via the vegetation patches. Indeed, hyacinth are often located close to the riverbanks, where waste may be more conveniently dumped. Some items then fragment into smaller particles, disentangle from the hyacinths, and enter the open water. A coupling of these accumulation-transport patterns is not to be excluded.

\section{Synthesis}

This study provides the first observational evidence that water hyacinths have a considerable impact on riverine plastic transport. Important temporal variations in plastic fluxes of several orders of magnitude were observed, highlighting the need for long-term continuous plastic monitoring. The importance of seasonal variability in macroplastic transport in the Saigon river, as already highlighted by van Emmerik, Strady, et al. ${ }^{15}$, prompts for investigations into the seasonality of water hyacinths and its role in plastic flux variability. We recommend that further research efforts focus on large-scale detection of floating vegetation, using Earth Observation (EO) satellites. Research shows that floating patches of hyacinth as well as plastics are detectable from space ${ }^{22,31}$. The disintegration and growth cycles of hyacinths could also explain sudden peaks in plastic emitted into the oceans, but have yet to be studied.

Further quantification of the macroplastic flux transported in water hyacinths at different seasons is needed. We found large temporal variations in the ratio of entangled macroplastic (from 15 to 93\%), with high ratios correlating with peaks in plastic transport. Our measurement campaign lasted six weeks and took place between the end of April and the beginning of June, a season which marks the transition from the high plastic loads of the dry season to the relatively low plastic flux characteristics of the wet 
months ${ }^{15}$. Longer field measurement campaigns could provide more accurate estimates of the average flux transported by hyacinth, which could then be used as a proxy indicator for estimating plastic transport and emissions.

Monitoring efforts may also be expanded to other locations along the Saigon river to better understand plastic transport-sink patterns. Our study focused on one location, but the role of hyacinth may differ in upstream and downstream river segments. Furthermore, it is unclear if the plastic debris is introduced at HCMC or further upstream. Better understanding of the plastic input sources is required for a comprehensive monitoring scheme. Investigating other river systems is also crucial to ascertain whether the dominant role of floating vegetation in plastic transport is specific to the Saigon river or not. Given the high overlap between rivers that have been invaded by hyacinth and rivers that are polluted by plastics, we hypothesize that hyacinth may be a driving force of plastic emission into the ocean in many other watersheds.

In our study, we showed that plastic transport is mainly driven by the presence of hyacinths. However, it is possible that in certain configurations - for instance large floating patches on the riverbanks - the hyacinths act more as a barrier for dispersion than a means of transport. Recent studies prove the role of mangrove forests in trapping anthropogenic litter in estuarine ${ }^{12}$ and coastal environments ${ }^{13,32}$. Focus on the residence time, and spatial interactions between hyacinths and plastic and degradation rates could be beneficial in that sense. The routes of macroplastic and transport-storage-remobilization patterns related to hyacinth dynamics should certainly be investigated at different scales ${ }^{33}$. Again, EO may prove to be a crucial complementary approach for understanding the river system at synoptics scales. Additional field measurements, such as physical sampling, on the other hand, would be necessary for finer characterization of the fate of plastics once entangled in hyacinths.

We conclude that water hyacinths play a substantial role in macroplastic transport in the Saigon river, as $78 \%$ of the total plastics were found to be transported by hyacinth patches. In addition, the high positive correlation $(r=0.98)$ between entangled plastic and total plastic flux suggests that hyacinths are a substantial driver in spatiotemporal variation of plastic transport. The item composition differs, with larger items and mainly E-PS plastics predominantly associated with hyacinth, and foils and soft bags more likely to be observed as free-floating items. Additional research is required on the scalability and transferability of our findings to other locations along the Saigon, and other river systems worldwide.

\section{Data availability}

All data used for this work are uploaded on the 4TU repository. A DOI will be provided upon publication of the final manuscript.

\section{Authors' information}

\section{Corresponding author}

\section{*E-mail: louise.schreyers@wur.nl}

\section{Note}


The authors declare no competing financial interest.

\section{Acknowledgments}

The work of LS was supported by NWO Open Mind grant 18127. The work of TVE was supported by the 4TU.Federation Plantenna project. This study is part of the Plastic Plants project, supported by the ESA OSIP program.

\section{References}

1. Emmerik van, T. \& Schwarz, A. Plastic debris in rivers. WIREs Water 7, (2020).

2. Borrelle, S. B. et al. Predicted growth in plastic waste exceeds efforts to mitigate plastic pollution. Science $369,1515-1518$ (2020).

3. Lau, W. W. Y. et al. Evaluating scenarios toward zero plastic pollution. Science 369, 14551461 (2020).

4. Blettler, M. C. M., Abrial, E., Khan, F. R., Sivri, N. \& Espinola, L. A. Freshwater plastic pollution: Recognizing research biases and identifying knowledge gaps. Water Research vol. 143416 424 (2018).

5. Lebreton, L. \& Andrady, A. Future scenarios of global plastic waste generation and disposal. Palgrave Commun. 5, 1-11 (2019).

6. van Emmerik, T. et al. Seine Plastic Debris Transport Tenfolded During Increased River Discharge. Front. Mar. Sci. 6, 1-7 (2019).

7. Kurniawan, S. B. \& Imron, M. F. Seasonal variation of plastic debris accumulation in the estuary of Wonorejo River, Surabaya, Indonesia. Environ. Technol. Innov. 16, 100490 (2019).

8. Hurley, R., Woodward, J. \& Rothwell, J. J. Microplastic contamination of river beds significantly reduced by catchment-wide flooding. Nat. Geosci. 11, 251-257 (2018).

9. He, B. et al. Influential factors on microplastics occurrence in river sediments. Sci. Total Environ. 738, 139901 (2020).

10. Liu, Y. et al. Effects of anthropogenic discharge and hydraulic deposition on the distribution and accumulation of microplastics in surface sediments of a typical seagoing river: The Haihe River. J. Hazard. Mater. 404, 124180 (2021).

11. Gerolin, C. R. et al. Microplastics in sediments from Amazon rivers, Brazil. Sci. Total Environ. 749, 141604 (2020).

12. Ivar do Sul, J. A., Costa, M. F., Silva-Cavalcanti, J. S. \& Araújo, M. C. B. Plastic debris retention and exportation by a mangrove forest patch. Mar. Pollut. Bull. 78, 252-257 (2014).

13. Martin, C. et al. Exponential increase of plastic burial in mangrove sediments as a major plastic sink. Sci. Adv. 6, eaaz5593 (2020). 
14. Cozzolino, L., Nicastro, K. R., Zardi, G. I. \& de los Santos, C. B. Species-specific plastic accumulation in the sediment and canopy of coastal vegetated habitats. Sci. Total Environ. 723, 138018 (2020).

15. van Emmerik, T., Strady, E., Kieu-Le, T. C., Nguyen, L. \& Gratiot, N. Seasonality of riverine macroplastic transport. Sci. Rep. 9, 1-9 (2019).

16. Thamaga, K. H. \& Dube, T. Remote sensing of invasive water hyacinth (Eichhornia crassipes): A review on applications and challenges. Remote Sensing Applications: Society and Environment vol. 10 36-46 (2018).

17. CABI. Eichhornia crassipes (water hyacinth). In: Invasive Species Compendium. Wallingford, UK: CAB International. (2020).

18. IUCN. Water Hyacinth , an Invasive Plant in the Lake Tanganyika Basin. (2017).

19. EDDMapS. Early Detection \& Distribution Mapping System. The University of Georgia - Center for Invasive Species and Ecosystem Health http://www.eddmaps.org/ (2020).

20. Sharma, A., Aggarwal, N. K., Saini, A. \& Yadav, A. Beyond biocontrol: Water hyacinthOpportunities and challenges. J. Environ. Sci. Technol. 9, 26-48 (2016).

21. Ongore, C. O., Aura, C. M., Ogari, Z., Njiru, J. M. \& Nyamweya, C. S. Spatial-temporal dynamics of water hyacinth, Eichhornia crassipes (Mart.) and other macrophytes and their impact on fisheries in Lake Victoria, Kenya. J. Great Lakes Res. 44, 1273-1280 (2018).

22. Dogliotti, A. I., Gossn, J. I., Vanhellemont, Q. \& Ruddick, K. G. Detecting and Quantifying a Massive Invasion of Floating Aquatic Plants in the R í o de la Plata Turbid Waters Using High Spatial Resolution Ocean Color Imagery. Remote Sens. (2018) doi:10.3390/rs10071140.

23. Lebreton, L. C. M. et al. River plastic emissions to the world's oceans. Nat. Commun. 8, 1-10 (2017).

24. Nguyen, T. T. N. et al. Nutrient budgets in the Saigon-Dongnai River basin: Past to future inputs from the developing Ho Chi Minh megacity (Vietnam). River Res. Appl. 36, 974-990 (2020).

25. van Emmerik, T. et al. A Methodology to Characterize Riverine Macroplastic Emission Into the Ocean. Front. Mar. Sci. 5, 372 (2018).

26. van Emmerik, T. et al. Manila River Mouths Act as Temporary Sinks for Macroplastic Pollution. Front. Mar. Sci. 7, 545812 (2020).

27. Geraeds, M., van Emmerik, T., de Vries, R. \& bin Ab Razak, M. S. Riverine plastic litter monitoring using Unmanned Aerial Vehicles (UAVs). Remote Sens. 11, 6-8 (2019).

28. González-Fernández, D. \& Hanke, G. Toward a harmonized approach for monitoring of riverine floating macro litter inputs to the marine environment. Front. Mar. Sci. 4, (2017). 
29. Dutta, A. \& Zisserman, A. The VIA Annotation Software for Images, Audio and Video. http://www.robots.ox.ac.uk/ (2019).

30. Lahens, L. et al. Macroplastic and microplastic contamination assessment of a tropical river (Saigon River, Vietnam) transversed by a developing megacity. Environ. Pollut. 236, 661-671 (2018).

31. Biermann, L., Clewley, D., Martinez-Vicente, V. \& Topouzelis, K. Finding Plastic Patches in Coastal Waters using Optical Satellite Data. Sci. Rep. 10, (2020).

32. Martin, C., Almahasheer, H. \& Duarte, C. M. Mangrove forests as traps for marine litter. Environ. Pollut. 247, 499-508 (2019).

33. Liro, M., van Emmerik, T., Wyzga, B., Liro, J. \& Mikuś, P. Macroplastic storage and remobilization in rivers. Water (Switzerland) 12, 22-29 (2020).

(1) 
Supporting Information to "Plastic plants: Water hyacinths as driver of plastic transport in tropical rivers"

MANUSCRIPT TITLE: Plastic plants: Water hyacinths as driver of plastic transport in tropical rivers

AUTHORS: Louise Schreyers ${ }^{1}$, Tim van Emmerik ${ }^{1}$, Thanh Luan Nguyen ${ }^{2}$, Evelien Castrop ${ }^{1}$, Ngoc-Anh Phung $^{3}$, Thuy-Chung Kieu-Le ${ }^{3,4}$, Emilie Strady ${ }^{5}$, Lauren Biermann ${ }^{6}$, Martine van der Ploeg ${ }^{1}$

${ }^{1}$ Hydrology and Quantitative Water Management Group, Wageningen University, Wageningen, The Netherlands

2École Polytechnique de Montréal, Montréal, Canada

${ }^{3} \mathrm{Ho}$ Chi Minh City University of Technology (HCMUT), Ho Chi Minh City, Vietnam

${ }^{4}$ Vietnam National University Ho Chi Minh City, Ho Chi Minh City, Vietnam

${ }^{5}$ Aix-Marseille University, Mediterranean Institute of Oceanography (MIO), Marseille, Université de Toulon, CNRS/IRD, France

${ }^{6}$ Plymouth Marine Laboratory, Prospect Place, Plymouth, UK

${ }^{*}$ Corresponding author

No of figures: 2

No of pages: 4

\section{Text S1 Calculation and extrapolation of plastic flux based on visual counting}

Plastic fluxes were estimated as follow:

$$
P_{i}=\frac{N_{h, i}}{t_{h, i}}+\frac{N_{f, i}}{t_{f, i}}
$$

With total plastic flux $P_{i}$ [items/min] for segment $i$, counted items inside the hyacinth $N_{h, i}$ during observation time $t_{h, i}[\mathrm{~min}]$ for segment $i$, and counted free-floating items $N_{f, i}$ during observation time $t_{t, i}$ [min] or segment $i$.

The total plastic flux for the entire river width $P_{\text {tot }}$ was estimated using

$$
P_{t o t}=\left(\sum_{i=1,2,3}^{n} \frac{P_{i}}{W_{i}}\right) \cdot W
$$

With observation width of each segment $w_{i}$ and total river width $W$.

\section{Text S2 - Data acquisition of UAV images}

The DJI Phantom 4 Pro UAV has a FC6310 camera, equipped with a one-inch CMOS sensor with a maximum resolution of 20 megapixels. This drone has a good camera resolution (5472 x 3648 pixels) and two tracking system - GPS and GLONASS - for localization.

The flights were programmed using the DJI GS Pro App. We defined 22 waypoints every $15 \mathrm{~m}$. Overall, the flights covered the full width of the river. Precautions were taken to minimize blurry images: a 'stop and go' mode was chosen, the camera shot interval was set at 2 seconds (the highest possible for the Phantom 4 Pro) and the autofocus mode was disabled. The hovering time for each waypoint was set at 
14 seconds, to stabilize the device before shooting several images. The images were captured at nadir, i.e. perpendicular $\left(90^{\circ} \pm 0.02^{\circ}\right)$ to the direction of the flight, to facilitate surface calculations. The drone operated automatically, from take-off to landing. The memorization of the flight plans allowed several scans along the two river transects defined. Each flight lasted approximately ten minutes. The flights were carried out by qualified UAV pilots following Vietnamese aviation rules.

The aerial surveys were conducted at two altitudes. The scans along the river transepts were scheduled at $5 \mathrm{~m}$ from the chart datum (derived from the lowest astronomical tide). A few images $(n=11)$ were captured at $15 \mathrm{~m}$ of altitude above the chart datum, usually in the middle section of the river. These images were retained for items count analysis and discarded for statistics on spatial distribution and temporal variability.

A

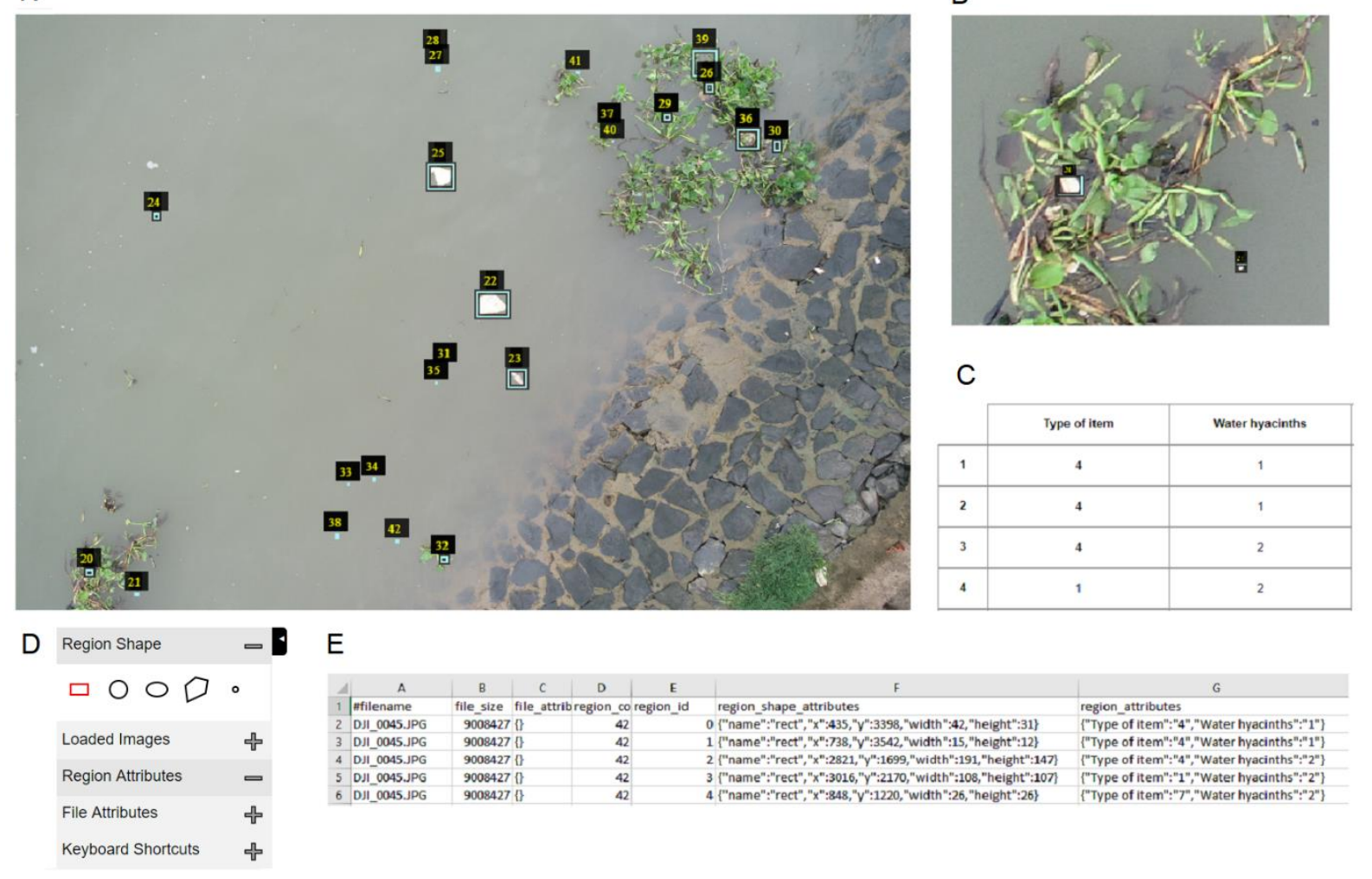

B

C

\begin{tabular}{|l|l|l|}
\hline 1 & 4 & 1 \\
\hline 2 & 4 & 1 \\
\hline 3 & 4 & 2 \\
\hline 4 & 1 & 2 \\
\hline
\end{tabular}

Figure S1. VIA tool web-browser interface. The main view window (A) shows a photograph, taken close to the riverbank, with typical small patches of water hyacinths with a few items aggregated. The zoomin function $(B)$ enables closer inspection of the items and the drawing of rectangular bounding box. The region attribute panel $(C)$ shows the main attributes filled in after the identification of an item. (D) shows the main functions available to the user. $(E)$ is a sample .csv file with all the attributes per item annotated.

\section{Text S3 Color filtering and area estimates}

The Open CV library is used for computer vision and color filtering operations. The color segmentation functions enable to identify regions with a specific color, using the RGB channels of images. In this case, the upper and lower thresholds in the RGB color space were defined for masking the green areas corresponding to floating vegetation (fig. S2). Due to differences in the background reflectance, 

image or group of images. This was done by trial and error tests.
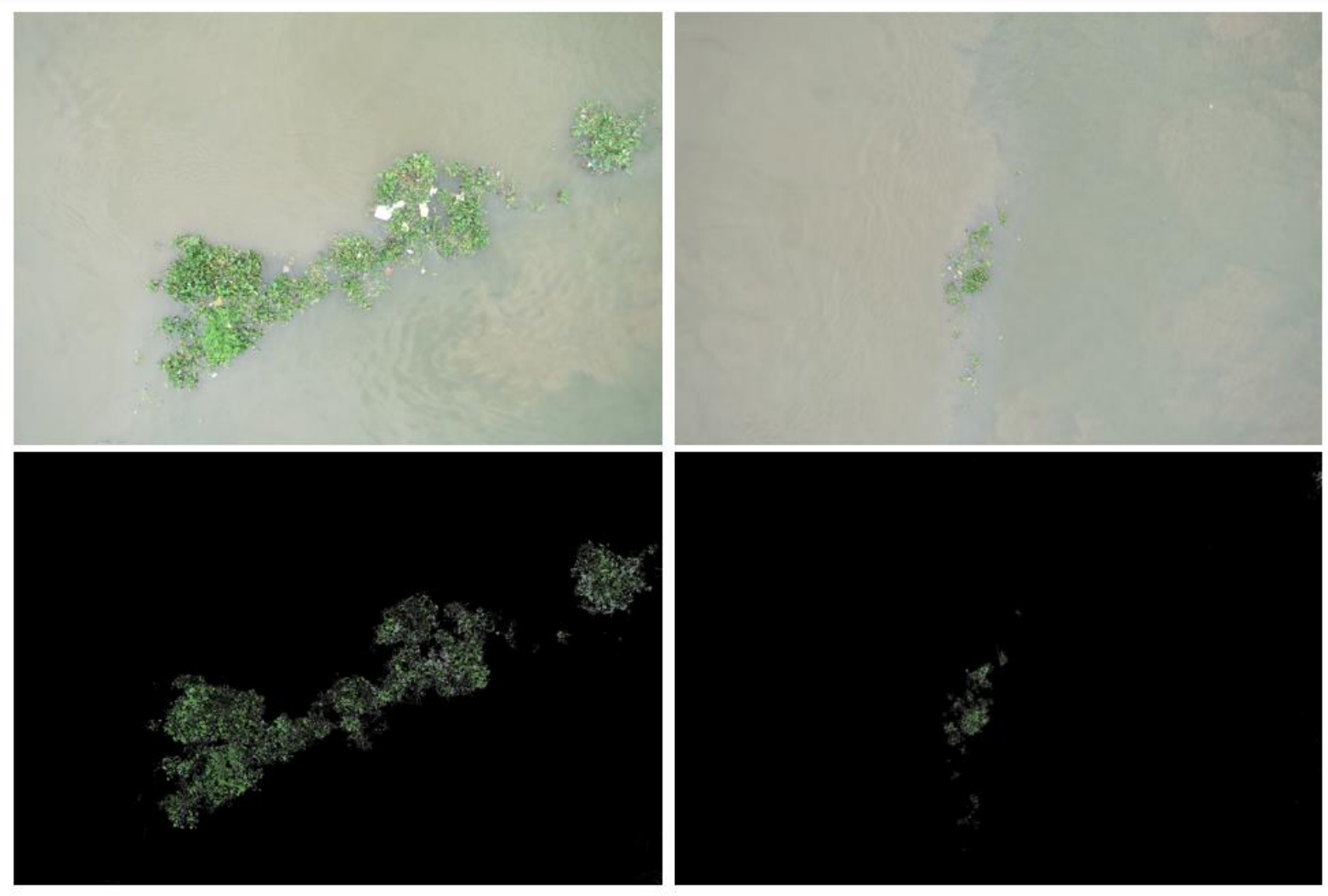

Figure S2. Examples of images with visible large patches of water hyacinths (top) and color filtering outputs for detecting floating hyacinth patches (bottom).

A total of 86 images were initially analyzed using color filtering, corresponding to the images with visible floating vegetation. From this collection, images with very small organic debris components - such as a floating branch or leaf - and those were the color segmentation did not perform well were discarded ( $\mathrm{n}$ $=11$ ). These included aerial images showing large number of false positives detected in open water or riverbanks. A final collection of 75 images were thus retained for color segmentation analysis.

Given the variations in the water level due to the tidal influence, the actual flying elevation from the drone standpoint (at a time t) $\mathrm{H}_{\mathrm{f}}$ was adjusted by correcting the flying elevation from chart datum as below:

$$
\mathrm{H}_{\mathrm{f}}=\mathrm{H}-\mathrm{H}_{\mathrm{s}}
$$

Where $\mathrm{H}$ is the elevation from chart datum and $\mathrm{H}_{\mathrm{s}}$ is the water height registered at a time t. The water elevation was manually measured before the take-off of the drone and considered stable throughout the whole flight duration (approximately 10 minutes).

Once the flying altitude was determined, the ground sampling distance $\left(d_{g}\right)$ was calculated as follows:

$$
\mathrm{d}_{\mathrm{g}}=\frac{\mathrm{S}_{\mathrm{w}} \times \mathrm{H}_{\mathrm{f}} \times 100}{\mathrm{~F}_{\mathrm{r}} \times \mathrm{w}_{\mathrm{i}}}
$$


481 Where $S_{w}$ is the sensor width of the camera, $H_{f}$ is the flight height in meters, $F_{r}$ is the focal length of 482 the camera in millimeters and $w_{i}$ is the image width in pixels. The $d_{g}$ was determined for each drone 483 scan and for the set of images taken at a higher elevation. For the whole image collection, an average $484 d_{g}$ of $0.175 \mathrm{~cm} /$ pixel was found.

485 